ERRATA

\title{
Erratum to: Insurance Status, not Race, is Associated with Mortality After an Acute Cardiovascular Event in Maryland
}

Derek K. Ng, ScM ${ }^{7}$, Daniel J. Brotman, MD², Bryan Lau, PhD, MHS, ScM ${ }^{1,2}$, and J. Hunter Young, MD, $M H S^{1,2}$

'Department of Epidemiology, Johns Hopkins Bloomberg School of Public Health, Baltimore, MD, USA; ${ }^{2}$ Department of Medicine, Johns Hopkins Medical Institutions, Baltimore, MD, USA.

$\mathrm{J}$ Gen Intern Med 27(11):1569

DOI: $10.1007 / \mathrm{s} 11606-012-2214-2$

(c) Society of General Internal Medicine 2012

Erratum to: J Gen Intern Med

DOI: 10.1007/s11606-012-2147-9

F igure 1 in the original publication is missing a label on

$F$ the y axis. The corrected figure appears below.


Figure 1. Kaplan-Meier plots, stratified by index admission condition comparing insurance status and race. The grey lines represent the expected high-risk groups (underinsured and black race).

Corresponding Author: Derek K. Ng, ScM; Department of Epidemiology, Johns Hopkins Bloomberg School of Public Health, 615 North Wolfe Street, Room E7133, Baltimore, Md 21025, USA (e-mail: dng@jhsph.edu)

The online version of the original article can be found at http:// dx.doi.org/10.1007/s11606-012-2147-9.

Published online September 5, 2012 